\title{
The Cultivation of the Rumen Ciliate Entodinium simplex
}

\author{
By G. S. COLEMAN \\ Biochemistry Department, Agricultural Research Council, \\ Institute of Animal Physiology, Babraham, Cambridge
}

(Accepted for publication I3 March 1969)

\begin{abstract}
SUMMARY
Entodinium simplex has been maintained in vitro anaerobically and in the presence of bacteria in a salts medium containing autoclaved rumen fluid, wholemeal flour and dried grass. The protozoa divided at least every 3 days during more than $2 \frac{1}{2}$ years. The wholemeal flour could be replaced by a mixture of rice starch and washed bran but not by either separately; in the presence of this mixture population densities of over 60,000 protozoa $/ \mathrm{ml}$. were obtained. Omission of the autoclaved rumen fluid decreased the number of protozoa to $25 \%$ of this value. Evidence was obtained that it was the particulate matter in the rumen fluid that was an essential for growth.
\end{abstract}

\section{INTRODUCTION}

Over the last 25 years rumen Entodiniomorphid protozoa have been grown successfully in vitro several times, but the population densities reported have usually been low. Hungate (1942, 1943) maintained several diplodinia for over a year at population densities of less than I000/ml. Gutierrez \& Davis (I962) cultivated Epidinium ecaudatum in vitro for 5 months but obtained populations of only $1200 / \mathrm{ml}$. Clarke (1963) maintained Eremoplastron bovis in unspecified numbers for 5 months and mixed entodiniomorphs for somewhat longer, while Mah (1964) maintained up to 1000 Ophryoscolex purkynei/ml. for nearly 3 years with a mean generation time of $24 \mathrm{hr}$. The longest period of continuous cultivation of a single species has been 9 years (I959 to the time of writing) for Entodinium caudatum, by the present author. This protozoon has been maintained at a population density of $30,000 / \mathrm{ml}$. and divided every 2 to 3 days (Coleman, 1960).

Recently Jarvis \& Hungate (1968) maintained Entodinium simplex, dividing every $24 \mathrm{hr}$, for an unspecified time on a medium of ground wheat and grass. Although these authors reported protozoal counts up to $30,000 / \mathrm{ml}$. in the presence of certain additives, many of their cultures declined rapidly and inexplicably from these peak numbers, and steady-state population densities of only $8000 / \mathrm{ml}$. were obtained.

The present paper describes the successful cultivation of Entodinium simplex (Dogiel) for over 2 years in a buffered salts medium with wholemeal flour and dried grass as the sources of carbohydrate; a preliminary communication has already appeared (Coleman, 1968). Although the name Entodinium simplex is widely used and will be used in this paper, some authors, e.g. Zielyk (1961) and Lubinsky (1957), consider that this protozoon is the same as Entodinium dubardi dubardi (Buisson) and that this latter name, being the earlier, is the correct one. 


\section{METHODS}

Culture media. The standard medium consisted of $20 \mathrm{ml}$. autoclaved (II $5^{\circ}$ for $20 \mathrm{~min}$.) mineral salt solution; $4 \mathrm{ml} .5 \% \mathrm{NaHCO}_{3}$ (freshly prepared in autoclaved water); $0.6 \mathrm{ml}$. I \% L-cysteine $\mathrm{HCl}$ (neutralized immediately before use); I.0 ml. aqueous $\mathrm{I} \cdot 5 \%$ suspension of 'stone ground' wholemeal flour (W. Prewett Ltd., Stone Flour Mills, Horsham, Sussex); $3 \mathrm{ml}$. autoclaved rumen fluid (ARF-see below); $5 \mathrm{mg}$. dried grass (Coleman, $\mathrm{I} 960$ ); contained in a $50 \mathrm{ml}$. centrifuge tube; $\mathrm{CO}_{2}$ was then bubbled vigorously through the complete medium for $3 \mathrm{~min}$. and the tubes stoppered immediately with a rubber bung. The mineral salt solution contained $(\mathrm{g}$./100 $\mathrm{ml}$.): $\mathrm{K}_{2} \mathrm{HPO}_{4}, 0.49 ; \mathrm{KH}_{2} \mathrm{PO}_{4}, 0.38 ; \mathrm{NaCl}, 0.127 ; \mathrm{CaCl}_{2}$ (dried), $0.0035 ; \mathrm{MgSO}_{4} .7 \mathrm{H}_{2} \mathrm{O}$, 0.007 .

Sterile rumen fluid fractions. All rumen fluid was taken from Clun Forest wethers fed on hay and oats. After treatment of fresh rumen contents as described below the fractions were autoclaved (II $5^{\circ}$ for $15 \mathrm{~min}$.) under $95 \%(\mathrm{v} / \mathrm{v}) \mathrm{N}_{2}+5 \%(\mathrm{v} / \mathrm{v}) \mathrm{CO}_{2}$ in sealed McCartney bottles. The fresh rumen fluid was first strained through two layers of muslin and when autoclaved formed protozoa-containing autoclaved rumen fluid (PARF). This strained fluid was then centrifuged at $500 \mathrm{~g}$ for $3 \mathrm{~min}$. and the supernatant fluid when autoclaved formed ARF. This supernatant fluid was further centrifuged at $10,000 \mathrm{~g}$ for $20 \mathrm{~min}$. and the supernatant fluid from this centrifugation autoclaved to form autoclaved supernatant fluid (AS). The pellet from this second centrifugation was washed once in mineral salt solution (Coleman, 1958) and then, after suspension in the original volume of salt solution, was autoclaved to form autoclaved bacteria $(\mathrm{AB})$.

Source of protozoa. The protozoa for inoculation were prepared from the rumen contents of Clun Forest sheep fed on hay and oats. The rumen fluid was taken $6 \mathrm{hr}$ after feeding and strained through one layer of muslin to remove the larger food particles. The fluid was then allowed to stand in an $8 \times I$ inch $\left(20 \times 2.5 \mathrm{~cm}\right.$.) tube at $39^{\circ}$ for $2 \mathrm{hr}$ to allow the larger protozoa to fall to the bottom of the tube. The fluid from the top of the tube was then centrifuged at $600 \mathrm{~g}$ for about $3 \mathrm{~min}$. or until one drop of the supernatant fluid showed on microscopic examination Entodinium simplex as the only ciliate protozoon present.

Cultural conditions. The cultures were first established in $15 \mathrm{ml}$. centrifuge tubes containing only $10 \mathrm{ml}$. of standard medium and to which was added only $0.1 \mathrm{ml}$. of $\mathrm{I} \cdot 5 \%$ aqueous suspension of wholemeal flour. These tubes were inoculated with $\mathrm{I}$ to 5 drops of the centrifuged rumen contents containing Entodinium simplex, gassed with $\mathrm{CO}_{2}$, sealed with a rubber bung and incubated at $39^{\circ}$. Wholemeal flour ( $0 . \mathrm{I} \mathrm{ml}$. of $\mathrm{I} \cdot 5 \%$ aqueous suspension) and about $\mathrm{I} \mathrm{mg}$. dried grass was added to each tube every day and after Io to 14 days the medium was examined microscopically for the presence of $E$. simplex. In most experiments 50 to 100 protozoa $/ \mathrm{ml}$. were present after this time, but when none was visible in a drop of culture the incubation was continued for a further week. If there were still no protozoa present the culture was discarded, as were any tubes that were found at any stage to contain caudate protozoa. As it was easy inadvertently to transfer protozoa from one tube to another by interchanging rubber bungs or by droplets of culture on the end of the pipette used to gas the tubes, care was taken to ensure that each tube always had the same bung and that the pipette was flamed each time before use. When these precautions were not taken, a more 
vigorously growing contaminant protozoon, such as $E$. caudatum, could be rapidly transferred from one tube to all the others in a batch.

Two or three weeks after the initial inoculations the cultures were diluted with an equal volume of fresh medium containing $0.2 \mathrm{ml}$. aqueous $\mathrm{I} \cdot 5 \%$ suspension of wholemeal flour, and transferred to a $50 \mathrm{ml}$. centrifuge tube. The quantity of $1.5 \%$ wholemeal flour suspension added daily was gradually increased to $0.5 \mathrm{ml}$. and then doubled to $\mathrm{I} \cdot 0 \mathrm{ml}$. The cultures were diluted with an equal volume of fresh medium once a week for a month, after which time this was increased to twice each week. Stock cultures were maintained on the standard medium with the daily addition of $\mathrm{I} \cdot 0 \mathrm{ml} . \mathrm{I} \cdot 5 \%$ suspension of wholemeal flour and $2 \mathrm{mg}$. dried grass and were diluted with an equal volume of fresh medium twice a week, i.e. condition D 3-4 of Coleman (1960). The fresh medium contained twice the amount of wholemeal flour normally added, in order to maintain the final concentration constant.

Protozoal counts. The number of protozoa in a culture was estimated by blowing $0.5 \mathrm{ml}$. of the culture from a $\mathrm{I} \mathrm{ml}$. graduated pipette with a large hole at the tip into $5 \mathrm{ml} .0 .02 \mathrm{M}$-iodine and counting microscopically all the protozoa in $0.1 \mathrm{ml}$. of the mixture. Only those protozoa which showed no signs of disintegration were counted. Where the effect of a change in growth medium is reported, at least 3 weeks had been allowed to elapse before the number of protozoa present was estimated. Unless otherwise stated the number of protozoa in a culture was always estimated immediately before dilution of that culture.

Preparation of washed bran. Twenty g. of broad bran (H. F. \& E. Ison Ltd., Henison Granaries, Histon Rd., Cambridge) were placed in a $500 \mathrm{ml}$. measuring cylinder and shaken with $500 \mathrm{ml}$. tap water. The bran was sallowed to settle and the water removed by decantation. This washing procedure was repeated five more times or until the supernatant fluid was clear. The bran was then washed a further four times in distilled water, spread on a flat dish and allowed to dry at room temperature. When the bran was dry it was ground in a Lee Attrition Mill (Lee Engineering Co., Milwaukee, Wis., U.S.A.).

\section{RESULTS}

For the continued maintenance of Entodinium simplex in the presence of bacteria it was necessary to add fresh wholemeal flour to the protozoal cultures each day. When no such addition was made all the protozoa died within $40 \mathrm{hr}$ of the omission. At no stage after the initiation of the culture was it found necessary to replace the medium completely each day; stock cultures remained alive up to 3 weeks without the addition of fresh medium provided that wholemeal flour was added each day. When $E$. caudatum was grown in the presence of autoclaved rumen fluid it was necessary to replace the medium before dilution of the culture with an equal volume of fresh medium, i.e. condition $C_{3-4}$ of Coleman (1960). Fortunately it was possible to maintain healthy cultures of $E$. simplex by direct dilution with an equal volume of fresh medium twice each week. Attempts to decrease the mean generation time of the protozoa by dilution of the culture every 24 or $48 \mathrm{hr}$ instead of twice a week were only partially successful. After 3 weeks there were only I 100 protozoa $/ \mathrm{ml}$. when the cultures were diluted every day, as compared with $21,400 / \mathrm{ml}$. when the cultures were diluted every other day, and $26,900 / \mathrm{ml}$. under standard conditions when dilution was twice a week. The actual population densities obtained in individual experiments under standard 
conditions were variable and in ten experiments with a mean of $27,000 / \mathrm{ml}$. the range was 16,500 to $6 \mathrm{I}, 000 / \mathrm{ml}$. Although the maximum yield of protozoa, in terms of organisms present per protozoon present initially after a given period, was usually greatest when the cultures were diluted every other day, whole cultures occasionally died inexplicably under these conditions and it was safer to maintain stock cultures by dilution twice each week.

\section{The organisms}

The protozoa initially selected for the inoculation were the smallest $(44 \mu \times 26 \mu)$ non-caudate ciliate protozoa present in the rumen of sheep fed on hay and oats. Since at no time during the $2 \frac{1}{2}$ years that this culture has been maintained have any caudate protozoa been observed microscopically, the morphological form of the ciliates cannot be the result of the loss of a caudal spine as has been observed with some rumen protozoa in vitro (Coleman, I963; Clarke, 1963). In stock cultures the size of the ciliates was $40 \mu \times 25 \mu$ (range 35 to $50 \mu \times 23$ to $28 \mu$ ) which is very similar to that recorded for Entodinium simplex by Dogiel (1927).

\section{Effects of medium constituents}

The detailed effects of varying in turn each constituent of the standard medium and of adding other materials were as follows.

Wholemeal flour. The daily addition of wholemeal flour to a final concentration of $0.25,0.5$ or $1.0 \mathrm{mg} . / \mathrm{ml}$. resulted in protozoal populations of $12,500,20,600$ and $\mathbf{2 2 , 4 0 0}$ ciliates $/ \mathrm{ml}$, respectively. In the presence of the highest concentration of wholemeal flour the results were variable although the above result was typical of that obtained in about half the experiments made. However in some experiments fewer protozoa were present than when only $0.5 \mathrm{mg}$. wholemeal flour $/ \mathrm{ml}$. was added daily, whereas in others up to $50,000 / \mathrm{ml}$. were present. Replacement of the wholemeal flour in the standard medium by an equal quantity of rice starch decreased the population to $3,700 / \mathrm{ml}$. and replacement by maize, potato or wheat starch resulted in the death of the culture in 4 weeks. When the amount of rice starch added daily was decreased by half to $0.25 \mathrm{mg}$. $/ \mathrm{ml}$. the number of protozoa increased to $6100 / \mathrm{ml}$, , but at no concentration was a population density of over $7000 / \mathrm{ml}$. ever obtained. This poor growth on rice starch differentiates Entodinium simplex from $E$. caudatum which grew readily on both rice starch and wholemeal flour (Coleman, 1958, 1960).

Although most of the starch grains in wholemeal flour were larger than those in commercial rice starch, some were smaller. It was therefore possible that Entodinium simplex was living on the small grains in wholemeal flour but dying in the presence of rice starch and other starches because the grains were too large for it to engulf. This hypothesis was supported by the observations of Sugden (1953), who stated that $E$. simplex was unable to engulf rice starch grains and inferred that they were too large to be taken up. Unfortunately it has not been possible to substantiate this and $E$. simplex organisms in crude rumen fluid and in culture have been observed microscopically to engulf rice starch grains and the smaller grains in wholemeal flour. Some protozoa contained starch grains the diameter of which was nearly half that of the engulfing ciliate.

Bran and rice starch. Since one of the products of milling whole wheat to obtain white flour is bran, its effect on protozoal growth in the presence of rice or wheat 
starches was investigated. The bran was either used as commercially available, when it contained an appreciable amount of starch, or after washing with water to remove this starch. When ordinary bran was used as a replacement for wholemeal flour at approximately $0.5 \mathrm{mg}$. $/ \mathrm{ml}$. the number of protozoa decreased from 26,900 to $3900 / \mathrm{ml}$. but this bran had a slight stimulatory effect when added in addition to wholemeal flour (Table I). Washed bran supported only I Ioo protozoa/ml. However, when ordinary or washed bran was added in addition to rice starch the number of protozoa increased to approximately the population density obtained in the presence of wholemeal flour (Table I). However, with continued culture in the presence of rice starch $(0 \cdot 25 \mathrm{mg} . / \mathrm{ml}$.

Table I. Effect of various starches, bran and sterile rumen fluid fractions on the maintenance of Entodinium simplex

The experiment was made anaerobically in $50 \mathrm{ml}$. centrifuge tubes containing $20 \mathrm{ml}$. salts medium, $4 \mathrm{ml} .5 \% \mathrm{NaHCO}_{3}, 0.6 \mathrm{ml}$. I \% L-cysteine hydrochloride and the additions shown below, equilibrated with $\mathbf{C O}_{2}$. The cultures were diluted with an equal volume of fresh medium twice each week and fresh flour, starch or washed bran as indicated was added each day. The experiment was initiated with a culture grown on the standard medium and the number of protozoa were counted after maintenance for 3 weeks on the medium shown.

\begin{tabular}{|c|c|c|c|}
\hline & $\begin{array}{l}\text { Daily addition of carbohydrate } \\
\text { (mg./ml. medium) }\end{array}$ & $\begin{array}{l}\text { Rumen fluid fraction added } \\
(10 \%, v / v)\end{array}$ & $\begin{array}{l}\text { No. of proto } \\
\text { ml. cultur }\end{array}$ \\
\hline \multicolumn{4}{|c|}{$(10 / 0, v / 8)$} \\
\hline 0.5 & wholemeal flour & & \\
\hline & wholemeal flour, 0.6 bran & & \\
\hline $\begin{array}{l}0.5 \\
0.25\end{array}$ & $\begin{array}{l}\text { wholemeal flour, } 0.6 \text { washed bran } \\
5 \text { rice starch }\end{array}$ & & $36,3 c$ \\
\hline 0.25 & 5 rice starch, 0.6 washed bran & Autoclaved rumen fluid (ARF) & 30,40 \\
\hline 0.25 & 5 wheat starch & & \\
\hline $\begin{array}{l}0.25 \\
0.6\end{array}$ & 5 wheat starch, 0.6 washed bran & & $\begin{array}{l}8,4 C \\
3,9 c\end{array}$ \\
\hline & $\begin{array}{l}\text { bran } \\
\text { washed bran }\end{array}$ & & \\
\hline \\
\hline 0.5 & wholemeal flour & None & \\
\hline & & $\begin{array}{l}\text { AS* } \\
\text { PARF } \dagger\end{array}$ & $\begin{array}{l}16,7 \\
25,0\end{array}$ \\
\hline & & ARF $\ddagger$ & 29 \\
\hline & & $\mathbf{A B}$ & \\
\hline
\end{tabular}

* AS = rumen fluid centrifuged 10,000 $g$ supernatant, autoclaved.

$\uparrow$ PARF $=$ whole rumen fluid, autoclaved.

I ARF = lightly centrifuged rumen fluid, autoclaved.

$\S \mathrm{AB}=10,000 \mathrm{~g}$ centrifuged pellet from $\mathrm{AS}$, autoclaved = autoclaved bacteria.

daily) and washed bran ( $0.6 \mathrm{mg} . / \mathrm{ml}$. daily) the population density increased until, at the time of writing, cultures of Entodinium simplex had been maintained at population densities of over $60,000 / \mathrm{ml}$. for more than 6 months. The number of ciliates was dependent on the amount of washed bran and rice starch added daily up to at least $0.6 \mathrm{mg}$. of each $/ \mathrm{ml}$. (Fig. I). Unfortunately, at the higher concentrations of rice starch the population densities were liable to decrease to low values inexplicably, and to obtain stable densities the daily addition of only $0.25 \mathrm{mg} . / \mathrm{ml}$. was used.

To determine whether the essential factors in the bran persisted in the medium for more than $24 \mathrm{hr}$ the following experiment was made. In the presence of $0.25 \mathrm{mg}$. rice $\mathrm{starch} / \mathrm{ml}$. daily, the further addition daily of $0.6 \mathrm{mg}$. washed $\mathrm{bran} / \mathrm{ml}$. increased the number of protozoa from 6000 to $61,000 / \mathrm{ml}$. When the washed bran was added only 
every other day or twice a week the population density decreased to 36,300 and $30,800 / \mathrm{ml}$., respectively. Addition of twice the amount (i.e. $1 \cdot 2 \mathrm{mg}$. $/ \mathrm{ml}$.) of washed bran every other day increased the number to only $40,200 / \mathrm{ml}$., suggesting that some essential factor in the washed bran was only available when it was added each day. When the washed bran was autoclaved ( $115^{\circ}$ for $20 \mathrm{~min}$.) and then added daily at 0.5 to $\mathrm{I} \cdot 0 \mathrm{mg} . /$ $\mathrm{ml}$. the population density was about $36,000 / \mathrm{ml}$., showing that one or more of the essential factors in the bran was sensitive to heat. The washed bran was not replaceable by the following proteins: $0.3 \mathrm{mg}$. alpha protein $/ \mathrm{ml}$, $1 \cdot 2 \mathrm{mg}$. zein $/ \mathrm{ml}$. or $1 \cdot 2 \mathrm{mg}$.

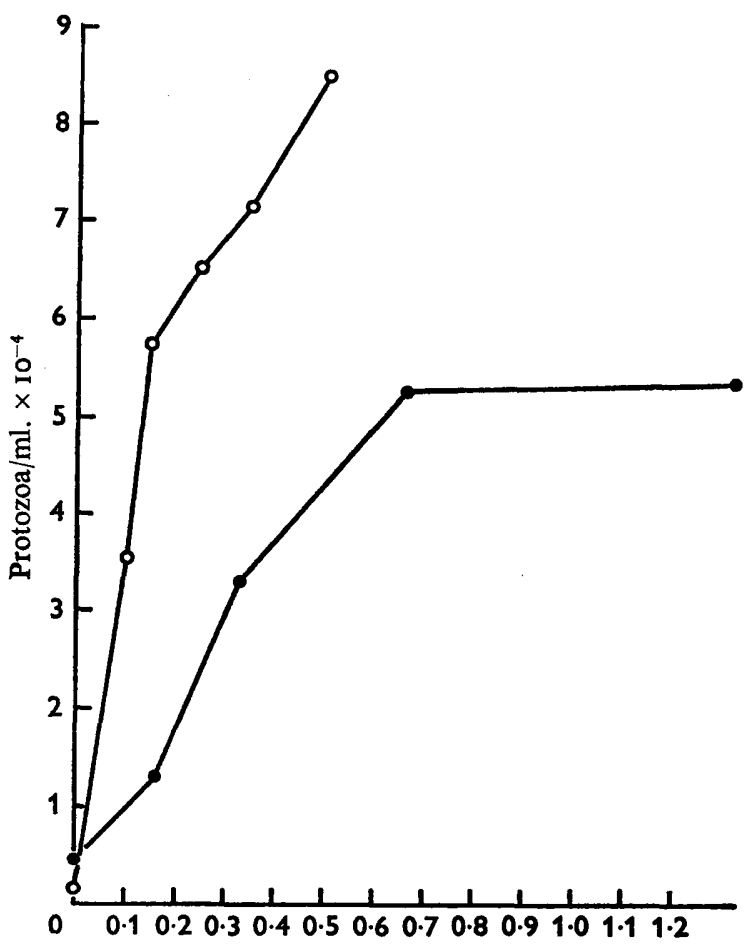

Rice starch or washed bran added daily $(\mathrm{mg} . / \mathrm{ml}$.)

Fig. I. Effect of quantity of rice starch or washed bran added daily on the steady-state population density of Entodinium simplex. The experiment was made under standard conditions on standard medium from which wholemeal flour was omitted. For the experiments on the effect of washed bran (-) $0.25 \mathrm{mg}$. rice starch $/ \mathrm{ml}$. was added daily and for those on the effect of rice starch $(\mathrm{O}-\mathrm{O}) 0.6 \mathrm{mg}$. washed bran $/ \mathrm{ml}$. was added each day.

casein $/ \mathrm{ml}$. However, in the presence of $0.3 \mathrm{mg}$. wheat gluten $/ \mathrm{ml}$. daily the steady-state population density was $70 \%$ of that in the presence of $0.6 \mathrm{mg}$. washed bran; but gluten had no further stimulatory effect when added in addition to washed bran. It is considered likely that the gluten preparation contained the same stimulatory factor as the washed bran, since they were both prepared from whole wheat and the proteins per se had no effect on the growth of the ciliates.

Although bran and rumen fluid both contain B group vitamins it was possible that the bran was acting as a source of thiamine which is known to be heat-labile. The effect of the daily addition of 20 or $200 \mu \mathrm{g}$. Difco yeast extract $/ \mathrm{ml}$. or 3,30 or $300 \mu \mathrm{g}$. 
thiamine/ml. was therefore investigated. These materials had no effect on the numbers of protozoa present after 3 weeks in the presence of rice starch under otherwise standard conditions. However, in one experiment out of four the daily addition of $300 \mu \mathrm{g}$. thiamine $/ \mathrm{ml}$. increased the number of protozoa by $60 \%$ after I week, although after 2 weeks the number had decreased to below that in the absence of thiamine.

Dried grass. In experiments made under standard conditions omission of dried grass from the standard medium, or from media in which the wholemeal flour was replaced by rice starch and washed bran, decreased the number of protozoa by 60 to $70 \%$ after I month, though some ciliates survived for more than 4 months.

Autoclaved rumen fluid. In the presence of 0,3 or $10 \%$ autoclaved rumen fluid (ARF) the numbers of protozoa present in a typical experiment were $8000,14,800$ and $37,000 / \mathrm{ml}$, respectively. Occasionally, however, an increase in the concentration of ARF from 3 to $10 \%$ had no stimulatory effect or was slightly inhibitory. Table I shows the effect of various rumen fluid fractions on the population density in an experiment in which double the standard concentration of wholemeal flour was stimulatory. In a series of experiments under standard conditions replacement of ARF by protozoacontaining autoclaved rumen fluid (PARF) or autoclaved bacteria (AB) had a small and variable effect $( \pm 30 \%)$ on the number of protozoa; but autoclaved supernatant rumen fluid (AS) always decreased the number to approximately half. This indicated that, as with Entodinium caudatum (Coleman, 1960), particulate matter was a better substrate for protozoal growth than soluble material.

In view of the findings of Jarvis \& Hungate (I968) that the addition of a protozoal extract (Clarke \& Hungate, I966) to the medium was stimulatory to the growth of Entodinium simplex, it was important to investigate the effect of this extract on the growth of this ciliate under the conditions used for the present experiments. The experiment was made in the standard medium in which the wholemeal flour was replaced by rice starch $(0.25 \mathrm{mg} . / \mathrm{ml}$. daily) and washed bran $(0.3 \mathrm{mg} . / \mathrm{ml}$. daily). After maintenance for 3 weeks under standard conditions there were 22,000 ciliates $/ \mathrm{ml}$. in the presence of $10 \%$ protozoal extract (prepared as described by Clarke \& Hungate, I966) as compared with $51,000 / \mathrm{ml}$. in the presence of $10 \%$ ARF. The addition of both materials together did not increase the number of protozoa.

Basal mineral salts. The standard mineral salt solution which contained phosphate and $\mathrm{NaHCO}_{3} / 100 \% \mathrm{CO}_{2}$ buffers was replaced by the mineral salt solution of Coleman (1958), which contained only phosphate buffer + acetate and was equilibrated with $95 \%(\mathrm{v} / \mathrm{v}) \mathrm{N}_{2}+5 \%(\mathrm{v} / \mathrm{v}) \mathrm{CO}_{2}$; this produced very variable results. In some experiments the protozoa died rapidly and in others they grew as well as in the standard medium. This indicated that these ciliates grew as well in the presence of $5 \% \mathrm{CO}_{2}$ as with $100 \% \mathrm{CO}_{2}$ provided that they survived the change of medium. Entodinium simplex did not survive in the medium for $E$. caudatum (Coleman, 1960), which contained rice starch as source of carbohydrate and also chloramphenicol, unless this was supplemented with $0.6 \mathrm{mg} . / \mathrm{ml}$. washed bran daily, under which conditions 50 to $100 \%$ of the numbers of protozoa present in the standard medium were found.

Temperature. Entodinium simplex was very sensitive to change in the growth temperature and after I week at $33^{\circ}$ or $41^{\circ}$ under otherwise standard conditions the numbers had decreased to 100 and $23,400 / \mathrm{ml}$, respectively, as compared with $33,300 /$ $\mathrm{ml}$. at $39^{\circ}$. No protozoa survived after I week at $44^{\circ}$. 


\section{Growth from small inocula}

In the experiments described above the minimum number of protozoa under standard conditions was usually greater than $10,000 / \mathrm{ml}$. after the dilution of a culture, and it was of interest to measure the growth of the protozoa from smaller inocula. Figure 2 shows growth curves for Entodinium simplex on standard medium and on standard medium with double the normal concentration of wholemeal flour from a $10 \%(\mathrm{v} / \mathrm{v})$

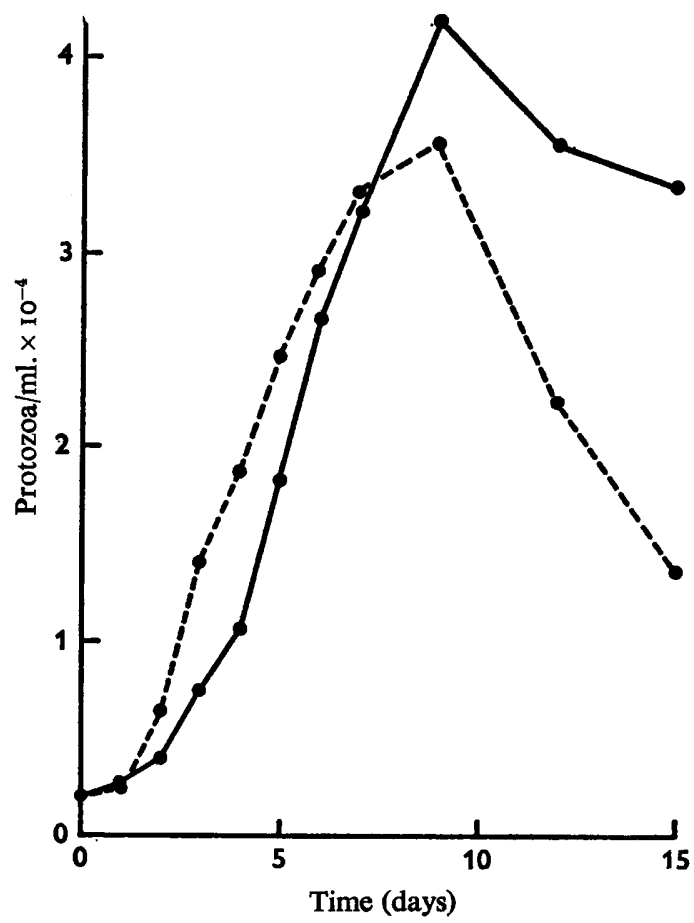

Fig. 2. Growth of Entodinium simplex from a small inoculum. The protozoa were maintained under standard conditions except that the cultures were not diluted with fresh medium twice each week. Standard medium (i.e. daily addition of $0.5 \mathrm{mg}$. wholemeal flour $/ \mathrm{ml}$.); - - - , standard medium with double the quantity of wholemeal flour (i.e. I.o mg./ml. daily).

inoculum of a stock culture ( 1800 ciliates $/ \mathrm{ml}$.). The generation time over the period of most vigorous growth with the daily addition of $0.5 \mathrm{mg}$. and $\mathrm{x} \cdot 0 \mathrm{mg}$. wholemeal flour $/ \mathrm{ml}$. was $2 \cdot 0$ and $\mathrm{r} \cdot 6$ days, respectively. However, once the maximum population density had been reached, the protozoa died more rapidly in the presence of the higher wholemeal flour concentration and this culture became more turbid because of bacterial growth on the excess starch. It was possible to maintain the protozoa on the standard medium with the daily addition of wholemeal flour $(0.25 \mathrm{mg} . / \mathrm{ml}$. daily $)+$ dried grass, by serial transfer of a $10 \%(v / v)$ inoculum once a week; one such culture was continued for over 30 weeks. Unfortunately this was not a reliable method for maintaining stock cultures because occasionally the protozoa died for no obvious reason. 


\section{DISCUSSION}

Several authors have reported the successful cultivation of rumen entodiniomorphid protozoa in Great Britain, the United States of America and New Zealand but the growth conditions used have varied considerably. None of the workers in the U.S.A. (i.e. Hungate, I942, I943; Gutierrez \& Davis, I962; Mah, I964; Jarvis \& Hungate, 1968) have found it necessary to use rumen fluid in their media and, with the exception of Jarvis \& Hungate (I968), have also found the addition of reducing agents to be unnecessary. In contrast those working elsewhere (i.e. Coleman, 1960; Clarke, 1963) have been unable to obtain good protozoal growth in the absence of either of these materials. Jarvis \& Hungate (1968) also found that soluble materials such as bovine serum and a protozoal extract increased the protozoal growth rate for a few days, whereas in the experiments described above with Entodinium simplex and previously with $E$. caudatum (Coleman, 1960) particulate matter (e.g. bran, washed mixed rumen bacteria) was more stimulatory than soluble materials and was effective for at least several months. It seems probable that soluble compounds are stimulatory for a few days before bacteria which grow on the new substrate have been selected and have grown heavily in the protozoal culture. In the present author's experience heavy bacterial growth has always been associated with a decreased number of protozoa $/ \mathrm{ml}$., possibly because of a decrease in $\mathrm{pH}$ value and the production of compounds toxic to the protozoa. In contrast, the use of solid food materials which were comparatively resistant to bacterial attack and were engulfed by the protozoa resulted in high stable population densities of entodinia. The cause of the other differences reported by authors in different countries is less apparent. The workers in U.S.A. and New Zealand used cattle ciliates, whereas the present author has always used those from sheep; perhaps apparently identical species of ciliate from different ruminants may behave differently in culture. It is also possible that initially identical ciliates may have evolved differently in host ruminants living in widely separated countries under different climatic conditions and therefore behave differently in culture.

Although the initial isolation of Entodinium simplex was made by using wholemeal flour as carbohydrate source, a mixture of rice starch + washed bran was subsequently found to give much better growth, especially after a few weeks of adaptation to this medium. Since many of the wheat starch grains were too large to be engulfed by $E$. simplex and must have been fermented by the bacteria in the cultures, the successful use of rice starch was probably associated with its complete utilization by the protozoa. The role of the bran in these cultures is uncertain, but it must supply some material, possibly a growth factor, not present in the starch or the bacteria living in the cultures. Unfortunately it was not possible to show with certainty a stimulation of protozoal growth by the addition of a solution of a mixture of growth factors (i.e. yeast extract) or of thiamine.

I wish to thank Mr G. A. Embleton, who inserted permanent rumen canulae in the sheep used as a source of rumen fluid, the members of the Sub-Department of Chemical Microbiology, Department of Biochemistry, University of Cambridge, for helpful criticism and advice, and Miss B. C. Hanzl for valuable technical assistance. 


\section{REFERENCES}

ClaRke, R. T. J. (1963). The cultivation of some rumen oligotrich protozoa. J. gen. Microbiol. 33, 40I.

Clarke, R. T. J. \& Hungate, R. E. (I966). Culture of the rumen holotrich ciliate Dasytricha ruminantium Schuberg. Appl. Microbiol. 14, 340.

Coleman, G. S. (1958). Maintenance of oligotrich protozoa from the sheep rumen in vitro. Nature, Lond. 182, 1104.

Coleman, G. S. (1960). The cultivation of sheep rumen oligotrich protozoa in vitro. J. gen. Microbiol. 22, 555.

Coleman, G. S. (1963). The growth and metabolism of rumen ciliate protozoa. Symp. Soc. gen. Microbiol. $13,198$.

Coleman, G. S. (I968). The cultivation and some properties of the rumen ciliate Entodinium simplex. J. gen. Microbiol. 53, viii.

DogIEl, V. A. (1927). Monographie der Familie Ophryoscolecidae. Arch. Protistenk. 59, I.

Gutierrez, J. \& DAVIs, R. E. (1962). Culture and metabolism of the rumen ciliate Epidinium ecaudatum (Crawley). Appl. Microbiol. ro, 305.

Hungate, R. E. (1942). The culture of Eudiplodinium neglectum, with experiments on the digestion of cellulose. Biol. Bull. mar. biol. Lab., Woods Hole 83, 303.

HuNGATE, R. E. (1943). Further experiments on cellulose digestion by the protozoa in the rumen of cattle. Biol. Bull. mar. biol. Lab., Woods Hole 84, 157.

JaRvis, B. D. W. \& Hungate, R. E. (I968). Factors influencing agnotobiotic cultures of the rumen ciliate Entodinium simplex. Appl. Microbiol. 16, 1044.

LUBINSKY, G. (1957). Studies on the evolution of the Ophryoscolecidae (Ciliata; Oligotricha). I. A new species of Entodinium with 'caudatum', 'loboso-spinosum' and 'dubardi' forms and some evolutionary trends in the genus Entodinium. Can. J. Zool. 35, I I I.

MAH, R. A. (1964). Factors influencing the in vitro culture of the rumen ciliate Ophryoscolex purkynei Stein. J. Protozool. II, 546.

Sugden, B. (1953). The cultivation and metabolism of oligotrich protozoa from the sheep's rumen. J. gen. Microbiol. 9, 44 .

ZIELYK, M. W. (196I). Ophryoscolecid fauna from the stomach of the white-tailed deer (Odocoileus virginanus borealis) and observations on the division of Entodinium dubardi Buisson, 1923 (Ciliata; Entodiniomorpha). J. Protozool. 8, 33. 